\title{
Empowerment and the challenge of applying transition management to ongoing projects
}

\author{
Flor Avelino
}

Published online: 29 October 2009

(C) The Author(s) 2009. This article is published with open access at Springerlink.com

\begin{abstract}
This article explores the relation between empowerment and long-term policy design. More specifically, it studies the empowerment aspect of a specific long-term policy design, transition management (TM), both theoretically and empirically. First, the respective bodies of literature on empowerment and TM are synthesized and four theoretically (dis)empowering aspect of TM are discussed. On that basis, four research questions are distilled as a framework for empirical analysis. Second, an empirical account is given of challenges that came up during the application of TM in ongoing projects, and these challenges are analyzed in terms of (dis)empowerment, following a critical line of argument. Third, a more instrumental line of argument distils lessons for TM, by applying empowering insights to design strategies on how to deal with the upcoming challenges of TM. The challenges, analyses, and lessons are summarized in a table at the end. In conclusion, the theoretical and empirical findings are related to a discussion on long-term policy design more generally.
\end{abstract}

Keywords Empowerment · Transition management · Long-term policy design · Participation · Sustainable transport

\section{Introduction: the micro-politics of long-term policy design}

Long-term policy designs that build on 'participative processes' and 'social learning' tend to presuppose certain actor qualities. This can lead to an ironic situation in which policies that are designed to 'empower' people, in themselves require people to already be 'empowered', in terms of being able enough to implement the new policy design. This article zooms in on the micro-politics of a new long-term policy design. The purpose is to unravel how highly ambitious policy goals as formulated in strategic circles 'land' in ongoing practices at operational levels (Pressman and Wildavsky 1973). As new policy designs carry direct

F. Avelino ( $\square)$

Dutch Research Institute for Transitions, Faculty of Social Sciences, Erasmus University Rotterdam, P.O. Box 1738, 3000 DR Rotterdam, The Netherlands

e-mail: avelino@fsw.eur.nl 
implications for "who gets what, when, and how" (Lasswell 1936 in Schneider and Ingram 1993), it is important to assess how new policy designs impact actors at various levels of policy implementation. This includes behavioral assumptions that underlie design and selection of policy tools (Schneider and Ingram 1990). While public policies attempt "to get people to do things that they might not otherwise do" or to "enable people to do things that they might not have done otherwise," it often occurs that these people "lack incentives or capacity to take the actions needed" or "disagree with the values implicit in the means or ends" (Schneider and Ingram 1990, pp. 513-514). This article will address the ironies of imposed empowerment, as well as possible strategies to deal with them.

In line with the overall theme of this special issue (Voß et al. 2009), the application of transition management in the Netherlands is taken as a case-study. One of the main purposes of transition management is to empower change-agents, 'niches' and 'frontrunners', to reach a sustainable society, if necessary by challenging, transforming or replacing existing 'regimes' (Rotmans et al. 2001; Rotmans 2003, 2005). Literature on transition management states that "the ultimate goal of transition management should be to influence and empower civil society in such a way that people themselves shape sustainability in their own environments, and in doing so contribute to the desired transitions to sustainability" (Loorbach 2007, p. 284, emphases added). The transition management approach has gained much attention from policy-makers and managers (Kemp and Rotmans 2009). It has been applied in various policy contexts, one example being the Dutch transport sector. In 2005, the Dutch Cabinet presented the latest Mobility policy plan, in which 'transition management' was mentioned as an innovation strategy for the long term. ${ }^{1}$ Subsequently transition management was applied in various 'sustainable transport' programs and projects. One of these programs concerns the organization Transumo, which consists of 22 different projects.

In this article, we look at three of these Transumo-projects. None of the projects were designed 'according to' the prescriptive transition management model. Rather, participants were expected (by the Transumo organization) to use transition management concepts to analyze, evaluate, or (help) develop the ongoing process. Practitioners and researchers use the term 'transitioning' to refer to the application of transition management concepts to ongoing programs and projects. In the literature, 'transitioning' is described as a "metalevel instrument to transition ${ }^{2}$ a regular policy context" (Loorbach 2007, p. 272), for instance by starting with a "strategic transition arena on a small scale to explore alternative visions in an area where innovation and innovative visions are scarce" (ibid, p. 291). This is also referred to as the 'two-track approach', which serves to underline that a transition management process does not necessarily intend to replace mainstream policy; they can initially 'co-exist'. With time and patience, transition management ideas may spread out and have a transformational influence on mainstream policy. While this type of 'transitioning' aims primarily at (government) policy, it also affects ongoing projects at operational levels, as one 'transitioning strategy' is to "build on existing projects and

\footnotetext{
1 "In order to also enable a sustainable growth of the economy on the long term, a system jump is necessary, in which completely new technology and cooperation among government, consumers, and business has to lead to clean, quiet, and energy-efficient traffic and transport systems. Therefore, the cabinet chooses transition management to achieve sustainable mobility for the long-term and in relation with that innovation programmes (...) for the short term, where cost-effective measures are used to deal with acute problems" (Uitvoeringsagenda Nota Mobiliteit (Policy Document on Mobility) 2005, p. 65).

2 The transition management literature uses the word 'to transitionise': a direct translation from the Dutch word 'transitioneren'. As 'transitionise' is not an English word, while 'transition' is acknowledged as a verb by the English dictionary, I replaced 'to transitionise' by 'to transition' or 'transitioning'.
} 
experiments to transition these and by broadening and scaling-up and (re)defining visions" (ibid, pp. 291-292: emphasis added). ${ }^{3}$

The three Transumo-projects studied in this article fall under this 'transitioning' strategy. As such, these projects are not representative for the 'full-fledged' transition management model, which has been applied far more elaborately and successfully in other cases (Loorbach 2007), nor are they representative for the Transumo-organization as a whole. This article does not aim to evaluate or compare the three projects under study, the Transumo-program or the transition management approach. The aim is to describe identified challenges that came up in 'transitioning' these three projects. The reader is invited to look at these challenges from the perspective of managers and participants that work at the operational level. After these challenges have been described, this article aims to demonstrate how literature on empowerment, as offered in management studies, organizational psychology, and critical theory, can serve to interpret and explain the challenges that were empirically observed. Finally, this empowerment perspective is used to draw lessons for transition management, both for practice and research. In conclusion, the relation between empowerment and long-term policy design is reflected upon.

\section{Case-study: applying transition management to ongoing projects on sustainable transport}

At the end of 2003, the Dutch government decided to grant subsidies out of natural gas revenues to strengthen the Dutch knowledge economy in its innovative and societal needs, with the aim of improving the Dutch 'knowledge infrastructure' in fields that have a specific societal relevance, including transport. ${ }^{4}$ There are 37 of such applied research consortia that are funded through these gas revenue subsidies, which amount to a total of 800 million Euros (and a complex set of bureaucratic subsidy regulations). In many of these programs, transition management is partly applied, one of them being the program Transumo. Transumo (an abbreviation for 'TRAnsition to SUstuainable Mobility') was founded in 2004 and facilitates 150 organizations from public, private, and knowledge sectors to collaborate in applied research projects related to sustainable transport. Their ambition is "to accelerate/encourage the transition to sustainable mobility. This will be achieved by initiating, and establishing for the long term, a transition process that leads to the replacement of the current, supply driven, mono-disciplinary technology and knowledge infrastructure, with a demand driven, multidisciplinary and trans-disciplinary, participative knowledge infrastructure," which is supposed to lead to "advances that help to strengthen the competitiveness of the Dutch transport sector ('Profit') and to preserve and improve spatial and ecological ('Planet'), and social ('People') aspects of mobility." 5

Transumo has a turnover of 60 million Euros, of which $50 \%$ is provided by Transumo through government subsidy and the other $50 \%$ by project participants. The organizational structure of Transumo is visualized in Fig. 1.

Each project in itself is organized in various groups, e.g., a board, a 'project-leader' and his management team, facilitative staff, an advisory council and the 'project participants'.

\footnotetext{
3 'Transitioning' is much less elaborated than the full-fledged transition management-model, and currently being studied both theoretically and empirically by Van den Bosch and Rotmans (2008).

${ }^{4}$ Other fields considered as having societal relevance include water management, ICT, health care, agriculture, spatial planning, housing, construction etc. http://www.senternovem.nl/bsik/.

5 http://www.transumo.nl/Nl/Organisatie/Missie.aspx.
} 


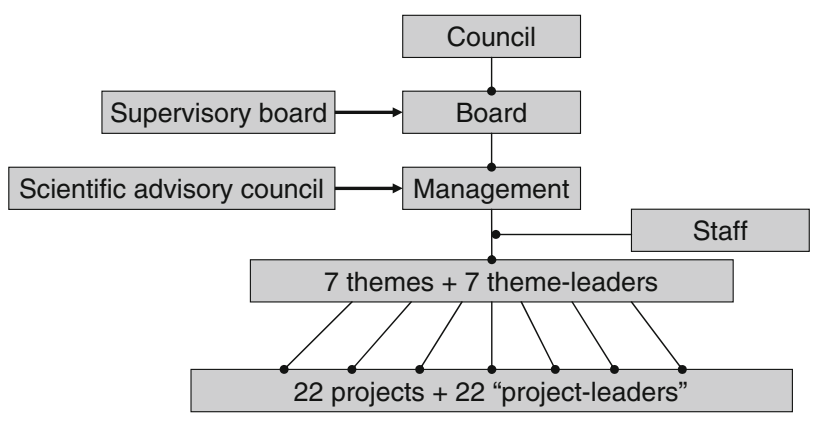

Fig. 1 Organizational structure Transumo

Participants consist of businesses, research institutes, consultancies, (semi-) governmental institutions, NGOs, and interest groups. This article reports empirical observations in three Transumo-projects. As discussed in the "Introduction" section, the aim is to address how strategic ambitions land at operational levels. As such, the empirical lens is focused on the project-level and the experiences and perceptions of its participants and 'project-leaders'.

The first two projects under study are called 'National Networks' and 'European Networks'. Both aimed to improve logistical networks (i.e., lowering costs, improving customer service, and decreasing negative societal effects) by combining applied research with pilot experiments. Both projects shared the same theme-leader and the same projectleader. The rest of the participants differed for each project, consisting of various research institutes, consultants, trade-organizations, and business representatives. The third project under study is referred to as 'the A15-project'. ${ }^{6}$ It aimed to find solutions for the emerging problems around the accessibility of the Rotterdam harbor from 2012 onwards, such as increasing congestion on the main road (the A15) and the negative environmental effects on the surrounding region resulting from the ever increasing freight transport. The project involved more than 30 organizations, including research institutes, (semi-) governmental organizations, environmental NGOs, various companies in the A15-region including the harbor company of Rotterdam, and a large trade-organization.

The selection of these three specific projects as case studies was based on the fact that the researcher had the opportunity to apply a combination of research methods that were necessary to observe the internal 'micro-politics' of projects. Research methods included ethnography, participant observation, action research, extensive document reviews, and dozens of interviews, during a total period of 2.5 years. These projects were studied with an open research question: how and to what extent is transition management applied within these projects? While there were considerable differences between the projects, they shared certain challenges that were experienced by participants and project-leaders. This section describes these challenges.

Struggling with transition-terminology

Transumo provides a 'format' in which project proposals and reports have to be delivered, ${ }^{7}$ in which project-leaders are required to report whether and how their project 'contributes

\footnotetext{
${ }^{6}$ The project is officially named 'From Maasvlakte to Hinterland: Sustainable Freight Transport as Challenge' but generally referred to as the A15-project, by both insiders and outsiders.

7 The purpose of these reports are described as 'essential input for the obligatory monitoring of projects' and 'formal accountability' to the program management concerning financial investments).
} 
to the transition to sustainable mobility', and how transition management is applied. Project-leaders noted that they had to 'translate' their project proceedings in to 'transition terminology', and that they found this difficult. Most participants in the Logistical Network projects seemed to equate the words 'sustainability', 'transition', and 'transition management' to a general and vague idea of change, improvement, and collaboration. One participant stated that these terms were never used during project meetings and that he had no idea what transition was supposed to mean. Others emphasized that these terms were meaningless and just a matter of window-dressing. The notion of 'system innovation' was equated to innovation in general and 'innovation' was used to imply technological optimization. In order to comply with the 'people-planet-profit-balance' as required by Transumo, the tendency was to list the 'side-effects' of economic optimization that are indirectly beneficial for planet and people. In the 'annual reports' of the Logistical Network projects, it was mostly emphasized how 'increasing efficiency' and 'combining freight loads' led to cost reduction and speeding up traffic flows and how this was 'good for profit'. It was then also mentioned how this led to 'less transport' (in terms of less kilometers), and therefore also 'less noise' (i.e., good for 'people') and 'less emissions' (i.e., good for 'planet'). In this way, the primary goal of economic optimization was framed in terms of 'sustainability'. Participants acknowledged and confirmed this point, underlining that increasing efficiency and (thereby) creating profit was the primary aim of the projects.

In the A15-project, transition-terminology came with considerable disagreement. The 'first round' consisted of analyzing environmental and traffic related problems (through quantitative methods and stakeholder interviews), followed by identification of possible solutions. While the 'second round' of the project was supposed to give 'more attention' to environmental aspects and innovation, fierce discussions emerged on the issue of 'sustainable mobility' and 'transition management'. There was an opposition between those who wanted the project to be about 'sustainability' versus those who wished to focus on 'accessibility' of the harbor, and between those who called for 'long-term perspective' versus those demanding 'short-term results' (Avelino and Bressers 2008). These disagreements went far beyond friendly discussions as participants on 'both sides' threatened to leave the project on more than one occasion. Especially company representatives (the majority of stakeholders) were mentioned as the ones that 'only cared about the short-term' as they considered accessibility problems around the A15 to require urgent, short-term solutions. This posed a problem, as the A15-project was part of Transumo and was therefore supposed to focus on long-term sustainability. ${ }^{8}$ Moreover, the traffic models that were used could not capture radical alternative visions for the future even if they wanted to. During most of the project meetings, the discussions predominantly revolved around who was going to use what data through the use of what computer model. As the project was fragmented in a 'steering group', a company group, a management team, and a so-called group of 'knowledge workers', fundamental discussions about strategic goals were mostly kept to the management team or 'steering board', and hardly discussed with the 'knowledge workers', who unsurprisingly produced 'deliverables' that were not only criticized for not being 'innovative' enough, but also found to lack strategies on how to implement the technocratic solutions proposed on the basis of scenarios 'calculated' in models.

\footnotetext{
8 This was a formal goal of the project; as there were various other projects around the A15 that dealt with short-term solutions, this A15-Transumo-project had been specifically assigned to deal with the long-term.
} 
The position of project-leaders and administrative hassle

All participants had jobs with various other projects and obligations and had to continuously legitimize their participation in Transumo-projects to their 'home organization'. One participant explained that while the person who represented his organization in the steering board was 'in favor of transition management', his direct boss thought the whole transitionto-sustainability to be absolute nonsense and demanded concrete results, i.e., application of a specific computer model. Therein, the position of the project-leader was especially difficult: he had to deal with a large consortium of 30 stakeholders categorized in all these different project teams, the direct bosses of each and every individual participant and with Transumo's 'theme-leader', board and directorate with all their reporting requirements. Besides that, Transumo organized various workshops on how to deal with the challenges of 'the transition to sustainable mobility' and the application of TM. ${ }^{9}$ Such meetings were received with mixed feelings; some participants found it inspiring and helpful, others claimed it was vague, time-consuming, and a distraction from concrete project results. More importantly, for the projects under study, much of it came 'too late'.

During the period of this study, both the theme-leader and project-leader of the two Logistical Network-projects ended their involvement with the projects. They expressed their dissatisfaction with the process in interviews and in a letter and an email directed at Transumo. They mentioned several reasons for their departure, emphasizing administrative hassle, the lack of a clear mandate from Transumo, and the lack of additional subsidy necessary to carry out certain pilot experiments. They also complained that they had not received satisfactory support for 'transitions' and 'transition management', and that an evaluation of their projects on that basis was thus unjustified. The project-leader stated that Transumo had never explicitly requested him to include the transition approach as a leading frame, that the projects had been started without 'transition knowledge', and that retrospective evaluation of his projects in terms of transition potential was based on a new set of rules that was made up during the process and never adequately communicated to him.

\section{Unbalanced power relations and stereotypes}

Transumo projects involve 'powerful' participants such as large production companies or a harbor company, and relatively 'weaker' participants such as small governmental institutions and small research institutes. Various challenges emerged in the cooperation between project participants with differing backgrounds. Participants of Logistical Networks explained that transporting companies have an inferior position to production companies. ${ }^{10}$ This 'unsustainable' relationship was confirmed within the project, as production companies had the upper hand in project meetings while representatives of transporting companies were afraid to open their mouth. Other conflicts emerged as the largest company representative complained that the main researcher involved in the project had 'no clue about business' and was only interested in getting research data without giving anything useful in return. Others complained that this company wanted to merely use the research results to make profit while not being willing to contribute to the

\footnotetext{
${ }^{9}$ During these workshops project-leaders present their concrete challenges to each other, and 'transition researchers' are invited to help structure the discussion and offer suggestions on how to move on.

10 As production companies mostly choose transporting companies that can offer the cheapest transport, transporting companies are involved in a fierce competition, a 'race to the bottom'.
} 
production and sharing of knowledge, while this was the aim of Transumo-projects. In the A15-project, business representatives complained that the process was taking too long, failed to produce concrete results and lacked action; representatives of environmental organizations commented that the A15-project was nothing but a 'toy' of the Rotterdam harbor company, while government representatives commented that 'yet again' it showed that Transumo-projects were nothing but 'a hobby for professors'.

Inhabitants of the A15-region and smaller transporting companies were not involved in the project at all, even though they can be said to 'suffer' the most from the effects of unsustainable mobility. One main participant involved in the preparation of the A15project complained that he intended to include the 'people' aspect of sustainability by involving 'truckers' (i.e., small transporting businesses) and local politicians that could represent the interests of surrounding inhabitants, but that there was no 'space' in the project to do so. We, thus, face a situation in which a national policy ambition covered by a subsidy of 800 million Euros for applied research, results in projects that mainly feature researchers, consultants, large companies, trade-organizations, and governmental institutions, while other segments of society remain uninvolved.

\section{‘Transitioning' ongoing projects}

In the A15-project, it was decided that in the second round there would be two 'parallel trajectories'. As it seemed impossible to include a transition management approach within the 'regular trajectory', the addition of a 'transition trajectory' was supposed to 'make room' for an alternative long-term perspective. Many participants felt that they were incapable of the 'radical and alternative thinking' associated with transition management and that they 'needed outsiders' to do this. This 'transition trajectory' mainly consisted of two brainstorming sessions in which 'outsiders' were invited to explore alternative ideas for the middle and long-term (years 2027-2057). ${ }^{11}$ The 'transition trajectory' was not integrated with the 'regular trajectory', and the 'deliverable' that came out of it was produced in isolation and considered 'unrealistic' by those who read it.

In that way 'innovation', 'transition management', and 'long-term visions on sustainability' were left to this small 'side-project', while 'optimization', 'project management', and 'short-term solutions for accessibility problems' remained the core business of the project. Participants commented that the 'transition trajectory' had some effect on the regular trajectory 'in spirit' (which is why it was also referred to as an 'innovation impulse'), and that it inspired the 'third round' of the project. In this round thematic 'working groups' were organized around seven challenges for the A15-region. ${ }^{12}$ The aim was to organize consortia around these themes and get stakeholders to sign an agreement on a long-term agenda related to short-term actions. The internal squabbling among project participants was partly 'solved' by dividing the responsibility for the different working groups between them. Some working groups integrated a long-term perspective and a transition management approach, while others did not. ${ }^{13}$

\footnotetext{
11 Resulting in future visions such as the A15-region as an 'experimental garden' for new technologies, radically different public-private partnerships for the A15-road, and the Rotterdam harbor as the engine of a bio-based economy.

12 These themes being: pricing policies, alternative energy use, clean vehicle technology, innovative government processes, transport prevention, freight transport, and logistical solutions, etc.

13 These 'working groups' were being organized at the end of the case-study, and the results or relative 'success' are unknown.
} 
Besides this 'two-track' approach, the idea was that managers could somehow use transition management concepts to improve the ongoing process, without necessarily starting a separate 'transition-like' initiative. While managers tried to do this at some point (some more than others), it did not work out. The theme-leader of Logistical Networksboth in his resignation letter to Transumo and in an interview-expressed a deep disappointment with the support he received to actually apply a transition management approach. Initially, the theme-leader was enthusiastic about transition management, as he firmly believed it would help him to lift his efforts in the logistical sector to a more strategic level. He had hoped that 'all the talk about transitions' would mean that he would receive practical and strategic support on how to spread innovative ideas on integrated logistical networks and how to get the right parties committed to practice them. This, however, did not happen. In a reaction to his resignation letter, the Transumo-organization noted (amongst many other things) that the theme-leader might have been 'too ambitious' and 'set his mountains to high'. Although the Transumo-organization did draw lessons from this experience and organized 'transition workshops' later on, it came too late for the managers that resigned. After the theme-leader and the project-leader decided to leave, the National Network projects ceased to exist as a Transumo project. The European Networks project received a new project-leader and became part of Transumo's 'transitioning trajectory'. ${ }^{14}$

\section{Analyzing challenges in terms of (dis)empowerment}

So far, we described challenges that came up during the application of transition management to ongoing projects, as empirically observed in three Transumo projects. These challenges can be summarized as follows: (1) participants struggled with (imposed) transition terminology, (2) project-leaders were reluctant and incapable of applying transition management and struggled with administrative hassle, (3) unbalanced power relations and stereotypes between participants were confirmed and enforced within and outside the projects, and (4) 'transitioning' ongoing processes disrupted and fragmented the projects (either through separate trajectories or resignation by project-leaders). How are we to explain and interpret these observed challenges? When we look from the perspective of transition management literature, we can argue that even though the label of transition management was used, it was 'not really' applied:

A danger lies in a haphazard and thin application of transition management so that it is hardly an improvement compared to regular (innovation oriented) policies. The 'label' transition management is increasingly used for projects and processes that are not fundamentally different from regular projects and processes, often stimulated by funding agencies that ask for 'transition' projects (without using strict or scientific criteria). In reality, these are often more optimization or innovation projects or trajectories than transition processes (Loorbach 2007, p. 287).

\footnotetext{
${ }^{14}$ In this transitioning trajectory, Transumo connects transition researchers to project-leaders with the aim of mutual learning on how to 'transition' an ongoing project, i.e., how to apply transition management to a project that has not been designed according to transition management. The end results of this transitioning process and the perception thereof by the project-leader are so far unknown to the author and have thus not been included in this study.
} 
One could argue that the three Transumo-projects under study were a 'thin application' of transition management, 'hardly an improvement compared to regular projects', a matter of 'optimization' and 'regular innovation' rather than 'transition' and merely using the label of transition management for funding purposes. While there may be a certain 'truth' in such conclusions, it is more constructive to understand how and why such 'thin applications' of transition management occur, and how they can be dealt with. ${ }^{15}$ This article aims to demonstrate how concepts on empowerment, as offered in management studies, organizational psychology and critical theory, can contribute to this effort. This section presents some of these empowerment concepts and consequently uses them to analyze the empirical observations in the previous section.

'Empowerment' knows a wide variety of interpretations. While managers often see empowerment as "giving people the power to make decisions" (Randolph 2000, p. 95), and the literature based on earlier research also defines empowerment in terms of delegating decision-making authority (Juhl et al. 1997, p. 103; Daft 1995 in Boje and Rosile 2001, p. 93), recent research has defined empowerment in more psychological terms (Spreitzer et al. 1999, p. 511) such as perceptions of control (Keller and Danserau 1995, p. 129) or intrinsic motivation (Conger and Kanungo 1988; Thomas and Velthouse 1990). This section addresses three different interpretations of empowerment: (1) intrinsic motivation (psychology), (2) sharing authority as opposed to hierarchy (management studies) and (3) the empowerment-disempowerment paradox (critical theory). Each of these interpretations of empowerment are shortly introduced and subsequently employed to analyze the four challenges that were identified within the three Transumo-projects.

\section{Intrinsic motivation}

Building upon earlier work on the need for self-determination and beliefs in personal selfefficacy (Deci 1975 and Bandura 1986 in Conger and Kanungo 1988). Thomas and Velthouse (1990) define empowerment as intrinsic motivation, operationalizing it through 'intrinsic task motivation' and 'task assessments'. ${ }^{16}$ Intrinsic motivation differs from extrinsic motivation in that the effort being invested in the former is not dependent on control or rewards imposed by others. Such intrinsic motivation requires individuals to have positive 'task-assessments' about their (daily) activities. These positive task assessments can be shortly characterized as follows:

- Impact: 'I can make a difference'

- Competence: 'I am good at what I do'

- Meaning: 'I care about what I do'

- Choice: 'I can determine what I do'.

The extent to which individuals are intrinsically motivated depends on interpretive processes through which individuals assess and evaluate their tasks, activities, and roles.

\footnotetext{
15 This confirms the point made by Loorbach, following the quote above: "The 'freedom of application', i.e., the possibility to interpret and use the transition management approach freely is inherent in the approach, which certainly in the beginning lacked preciseness. Even our own approach and model are still ambiguous in some sense and our thinking is continuously in development. It is, however, necessary to be reflective and analytically strict in evaluating and learning from the diversity of practices" (Loorbach 2007, p. 287).

16 Task assessments refer to the cognitions about a task; the way in which individuals assess a "task," defined as "a set of activities directed toward a purpose," either assigned or chosen (Thomas and Velthouse 1990, p. 668).
} 
The less impact, competences, meaning, or choice individuals think they have with regard to their daily tasks, the less intrinsically motivated they are, and the more dependent they become on extrinsic motivation (e.g., financial rewards or formal control).

When we apply these ideas to our empirical observations, we can argue that in the three projects under study transition-terminology was used out of extrinsic motivation rather than intrinsic motivation. Project documents were written and translated in transition terminology because this was 'expected' and formally 'required' by Transumo, not because the authors mastered or cared about the meaning of these concepts. The imposed transition-terminology seemed to have a negative effect on the participants' sense of impact, meaning, competence and choice. Because it was imposed from above participants had the feeling that they did not have a choice in applying it. Rather than being an 'origin' of the language they used, they were 'pawns' in a broader transition discourse. Moreover, transition concepts tend to illustrate how complicated and interconnected the transportation system is, how persistent unsustainability problems are, how much need there is for (more) radical system innovations, and how long it will take before this can happen. As the three projects were geared at concrete improvements of only one specific subsystem of "the mobility system', the confrontation with the ambitious transition discourse lowered participants sense of impact; instead of making them feel that they were making a difference with their project, it suggested the opposite.

While transition concepts are in theory especially suitable to create a sense of 'meaning' ${ }^{17}$ they hardly succeeded in doing that in these three projects. Many participants (including transporting engineers and practical businessman) found the transition terminology particularly difficult to understand (theoretical, abstract, overly ideological, etc.) and it did not provide them with a higher sense of meaning about what they were doing. Moreover, it made participants dependent on 'experts' that could 'explain' the transition terminology to them, a process in which it was often suggested that participants lacked necessary intellectual competences to 'understand' the philosophy on transitions. As such, not only did the use of transition terminology not succeed in providing participants with a sense of more choice, impact, meaning, and competence, it actually caused less of all four, thus having a negative impact on intrinsic motivation. ${ }^{18}$

In the A15-project, the two-track approach of 'transitioning' an ongoing project by starting up a transition trajectory 'on the side' and organizing an additional group, had a disempowering effect in that it took away the incentive for other participants to strive for a more innovative and long-term perspective within the regular project. It suggested that the 'regular participants' were incompetent. Rather than challenging them, a self-fulfilling prophecy occurred in which participants were given the impression that they were not innovative or risk-taking enough, and therefore they would also not act like it. In the two other projects, 'failed' attempts to apply transition management, and the judgment thereof

\footnotetext{
17 As they explicitly addresses subjective interpretations of sustainable development and future visions.

${ }^{18}$ It should be mentioned that it was not just the transition terminology that seemed to have this disempowering effect. The 'mainstream' discourse on mobility, and freight transport specifically, has various ingredients that can be disempowering. The tendency of both academics and practitioners to frame transport issues in quantitative economic and technological terms is disempowering in projects that (mainly) address organization and governmental challenges (as was the case in these three projects). Participants felt they had to produce concrete, short-term, quantifiable results, preferably a new technology that business could profit from, while ideally 'also' more 'environment friendly'. Although changing the mind-set throughout a sector or getting stakeholders committed to cooperate in public-private partnerships is just as hard as producing a profitable technology (if not harder), it tends to 'count for less'. It seems that it was the specific combination of imposed transition terminology with the quantitative transport discourse that was especially disempowering.
} 
by others, was disempowering up to the point of resignation. The theme-leader that resigned was known to be an especially inspiring, enthusiastic, and intrinsically motivated individual with a wide network of connections in the logistics sector, and a rare ability to get transporting companies enthusiastic to be involved in new logistical concepts developed in academia. As far as the theme-leader lacked competences, he himself was openly aware of it and explicitly requested support for the challenges he faced. This particular incident illustrates the risk of disempowering and 'loosing' individuals that initially had a high level of intrinsic motivation.

Hierarchy and the role of mid-level managers

Management studies emphasize that there is an inextricable linkage between empowerment, leadership, and innovation (Kanter 1983 in Spreitzer et al. 1999, p. 512). ${ }^{19}$ While this seems evident, less obvious insights relate to mid-level managers. These are often found to be the main 'resisters' of organizational transformation (Kanter et al. 1992). Researchers argue that this tendency of mid-level managers to resist change, can be addressed through a form of empowerment in which a mid-level manager is given the opportunity to not only 'manage' its subordinates but to also challenge its superiors, i.e., exert both 'downward' influence as well as 'upward influence' (Spreitzer et al. 1999, p. 513). However, this requires a 'shift from a hierarchical culture to a culture of empowerment' throughout an organization, which is a long and difficult process as these two cultures contrast in various ways (Randolph 2000).

Even when given the opportunity, many people do not 'choose' for a culture of empowerment, because new opportunities provided by empowerment also bring along risks and more responsibilities. While intrinsic motivation is generally believed to be beneficial, the majority of employees is accustomed to operate under extrinsic motivation and command-and-control processes (Randolph 2000, p. 96). Extrinsic motivation is a 'survival mechanism' in most work environments, and as a result individuals get 'attached' to it (Argyris 1998, pp. 102-103). To complicate things further, managers often simply do not know how to facilitate intrinsic motivation and do not receive the necessary support on how to do this. As a result they often attempt to facilitate intrinsic motivation through mechanisms that actually enforce extrinsic motivation, such as incentive schemes, higher compensation, better career paths, and recognition rewards. Not only do these systems of reward wear off with use; they also increase dependency (ibid).

Although Transumo involves some aspects of an empowerment culture (which are inherent to its project-based network structure), many aspects of hierarchical culture (see Table 1) were heavily present within and around the three projects under study. Projects were focused on planning rather than visioning, there was a focus on individual responsiveness (mostly by project-leaders) rather than team responsibility by all participants, there was an explicit 'pyramid' structure (boards, steering groups, management teams etc.), control and monitoring was based on top-down Transumo standards rather than "partnering for performance' or self-monitoring by participants, and project-leaders often complied with program formalities and stakeholders interests instead of making own judgments. Such hierarchical and formal structures-both at the program-level and at the project-

\footnotetext{
19 People with a high level of intrinsic motivation are more likely to have an innovative mind-set because "a high-level of self-confidence or self-efficacy is a prerequisite for embracing the inherent risk of challenging the status quo" (Spreitzer et al. 1999, pp. 512-513).
} 
Table 1 Hierarchical culture versus empowerment culture (source: Randolph 2000, p. 98)

\begin{tabular}{ll}
\hline Hierarchical culture & Empowerment culture \\
\hline Planning & Visioning \\
Command and control & Partnering for performance \\
Monitoring & Self-monitoring \\
Individual responsiveness & Team responsibility \\
Pyramid structures & Cross-functional structures \\
Workflow processes & Projects \\
Managers & Coaches/team leaders \\
Employees & Team members \\
Participative management & Self-directed teams \\
Do as you are told & Own your own job \\
Compliance & Good judgement \\
\hline
\end{tabular}

level-created an atmosphere of control, distrust, fear, risk-avoidance, and compliance, which is in direct opposition to all that is required to foster intrinsic motivation.

The 'theme-leaders' and 'project-leaders' in Transumo-projects can be compared to (mid-level) managers in large organizations. The Transumo project-managers in our casestudy felt that they were somehow supposed to apply transition management, but did not receive the necessary support on how to deal with subsequent dilemmas. They had to deal with steering groups, stakeholders, subsidizers, and other project-participants, and on top of that with Transumo's formalities. Not only did stakeholder-interests conflict within the project itself, they also conflicted with Transumo goals and expectations. To complicate things further, Transumo itself is also under scrutiny of supervisory bodies, and its board members, directors and facilitators also had differing opinions on the degree to which longterm transition ambitions and 'sustainability' should be aspired, and on the extent to which transition management should be applied within Transumo. Looking at this organizational whole, we see a hierarchical complex in which project-leaders received conflicting messages and were primarily preoccupied with keeping everyone above, under, and next to them satisfied, living in a continuous fear that subsidies might be removed. As a result, they increasingly worked on the basis of extrinsic motivation and it is thus not surprising that the project-leaders lacked the intrinsic motivation to 'really' apply transition management and transform their ongoing projects.

Empowerment-disempowerment paradox

Critical theorists argue that attempts to empower 'others' create a dependency relationship which (by definition) reinforces the dualism between the 'powerful' and the 'powerless', and that this process is actually disempowering (Hardy and Leiba-O'Sullivan 1998, p. 469; Boje and Rosile 2001, p. 102). Moreover, empowering one actor may involve the disempowerment of another actor. It has been argued that especially mid-level and lowerlevel managers are disempowered by empowerment programs that remove control from managers (Hardy and Leiba-O'Sullivan 1998, pp. 472-475). This 'paradox of empowerment' relates to the issue of power. While some suggest that power increases when it is shared by superiors with subordinates (Keller and Danserau 1995, p. 127), others emphasize that power cannot be shared or delegated, but only attained and exercised from within: power is a self-developing capacity and it is thus impossible to empower others 
(Follet 1941 in Boje and Rosile 2001). Critical theory furthermore holds that relations of power depend on "one's location in the system" and that one cannot alter these relationships at the interpersonal level without changing the system (Clegg in Boje and Rosile 2001, p. 111).

One can argue that the 'tripartite' Transumo-construct of 'demand-driven' research aims to empower business and governmental institutions by enabling them to co-determine the direction of applied research. While such 'transdisciplinarity' is an essential aspect of transition management (Kemp and Rotmans 2009), it can have a disempowering effect on project-leaders if they are incapable of standing up against the demands of powerful businesses and governmental institutions that participate in a project. In the three projects under study, we observed how unbalanced relations of power and stereotypes were confirmed and reinforced. The transition discourse on 'regimes' and 'niches' (Kemp and Rotmans 2009) is meant to empower the 'weaker' innovative actors to oppose, overcome, and transform actors that represent vested interests. However, in the three projects under study, participants tended to use the 'niche-regime' terminology to confirm the dominant position of 'regime-actors' as a 'given' rather than a something to be overcome. Managers feared that by involving more 'niche-actors' or by giving them more decision-making power, this might upset the 'regime-actors', such as members of the steering group (who could decide to end their involvement in the project, which would imply the redrawing of financial resources). There was a tendency to avoid public disagreement or fundamental discussions on sustainability (planet versus profit versus people), in order to 'keep everyone on board'. In the mean time underlying stereotypes and power struggles were quietly confirmed and enforced.

Projects featured business, science, and government, as their 'cooperation' was expected to contribute to 'a transition to a sustainable society'. These expectations were confirmed by transition management concepts and led Transumo to 'empower' businessrepresentatives, bureaucrats, and researchers, while empowerment of weaker segments of society remained invisible. This in turn also had disempowering effects on the project participants. Although this sounds paradoxical (as they were initially empowered), this paradox occurred as participants started feeling that their project was not 'making a difference'. It was striking to notice the cynical tone in which participants spoke of notions such as 'sustainable mobility' and 'transition'. Even though the importance of these notions was underlined and confirmed all around in policy documents, program-ambitions and large bags of subsidy money, many participants failed to see how all these investments actually helped to improve society. As this decreased a sense of impact and meaning, the intrinsic motivation to make the projects part of 'a transition to sustainable mobility' diminished.

So far, three strands of literature on empowerment were discussed, and the provided insights were used to interpret, analyze, and discuss the transition management challenges that were identified in "Case-study: applying transition management to ongoing projects on sustainable transport" section. Table 2 below offers an overview and summary of how the different empowerment insights apply to the empirically observed challenges.

\section{Empowerment lessons for transition management}

The literature on transition management frequently emphasizes that any tendency to institutionalize or control a transition management-process should be avoided: "the traditional policy-making paradigm of developing plans, strategies and implementing these in 
Table 2 Overview: empowerment insights on observed transition management (TM) challenges

\begin{tabular}{l} 
Observed TM-challenges \\
\hline Participants struggled with \\
(imposed) transition \\
terminology \\
\\
Project-leaders were reluctant \\
and incapable of applying \\
transition management and \\
struggled with administrative \\
hassle
\end{tabular}

Unbalanced power relations and stereotypes between participants were confirmed and enforced within and outside the projects
Empowerment insights on TM-challenges

Transition terminology had a negative impact on intrinsic motivation/ task assessments of participants, because it was: (1) imposed $=>$ negative impact on sense of choice, (2) overly ambitious $=>$ negative impact on sense of impact and (3) highly abstract $=>$ negative impact on sense of meaning and competence (as it made participants dependent on expert that could 'explain' transition terminology)

Project-leaders (=mid-level managers) lacked intrinsic motivation to apply TM. 'Fear' of risks and responsibilities that come with intrinsic motivation were enforced by hierarchical aspects of organizational context (including formal administrative hassle). Moreover, projectleaders did not receive sufficient timely support on how to apply TM in specific project context

'Transdisciplinary' and 'tripartite' design of organization empowered business and government to co-determine applied research. This was disempowering for research-oriented project-leaders who could not stand up against demands of powerful business and government participants. Participants who had a 'weaker' position in the sector also had inferior position in the project. The 'weakest victims' of unsustainable transport were not at all involved in the project, which had a negative effect on participants' sense of impact. Transition discourse on 'niches' and 'regimes', which is supposed to challenge regimes, was instead used to confirm the dominant position and strategic importance of regime-actors within the project

Not only was TM imposed top-down, this occurred at a later stage of ongoing projects, suggesting that ongoing processes were unsatisfactory ( $=>$ negative impact on sense of impact and competence). As the projects were already embedded in a hierarchical organisational context, TM was imposed through mechanisms that enforce extrinsic motivation (i.e., formal accounting, forms, reports etc.). Moreover, the innovative actor-selection prescribed by TM conflicted with the fact that projects participants had already been selected. Incumbent participants were given the impression that they were 'not innovative or risk-taking enough for TM' and that 'outsiders' were necessary ( $=>$ negative impact on sense of competence)

a rather straightforward manner has to be replaced by a more holistic, refined, and integrated perspective" (Loorbach 2007, p. 53). However, when 'transitioning' ongoing programs and projects, these 'traditional policy-making paradigms' and related hierarchical structures are already in place. Therein, the risk is that transition management concepts are imposed in a top-down manner, thereby (unwillingly) creating a 'superficial' use of transition management concepts on the basis of extrinsic motivation, thereby hampering the intrinsic motivation to 'really' work with the ideas of transition management. This section explores what we can learn from empowerment insights, on how to deal with these challenges.

\section{Using transition discourse}

The idea of a 'transition to a more sustainable system' functions as a story-line that can be interpreted in different ways, bringing people together in a common endeavor to reach higher societal goals (Smith and Kern 2007). A new story-line can empower people and 
help them to form a so-called 'discourse-coalition' around a new set of ideas and ambitions (Hajer 1995). For instance, in the A15-project, participants emphasized that the major challenge concerned fierce disagreements on 'long-term perspective' versus 'short-term results' or 'sustainability' versus 'accessibility' (Avelino and Bressers 2008). It so happens that transition management is especially designed to link long-term to the short-term ${ }^{20}$ and to treat 'sustainability' as an integrative and context-specific notion that stakeholders demarcate for a specific region or sector. ${ }^{21}$ Therein, economic viability and accessibility are part of long-term 'sustainability' in the A15-region, so it is unnecessary to treat 'sustainability' and 'accessibility' as opposites. Transition management-tools, such as transition scenario exercises (Sondeijker et al. 2006) or participatory system analyses (Grosskurth and Rotmans 2005) could have been used to deal with the challenges in the A15-project, by facilitating project meetings in terms of problem-structuring, systemanalyses, and scenario-exercises. However, participants did not regard transition management in this instrumental manner, far from it. Instead, the majority associated transition management with a 'vague' long-term perspective, abstract ideals and the 'planet'-aspect of 'sustainable mobility'. While transition management theoretically stands for an integrated perspective, it was brought in to counterbalance the prevailing short-term, economic focus. Therefore, the transition management approach was equated to 'choosing sides' in favor of participants prioritizing environmental aspects and long-term goals, and 'against' those concerned about economic aspects.

The problem in the projects under study was the top-down manner in which the transition discourse was imposed at a relatively late stage of the process, despite of the apparent tensions with the project themes (i.e., optimization, efficiency, and accessibility in the freight transport sector). From an empowerment perspective, the suggestion is to carefully consider whether transition management is at all appropriate, applicable or helpful for an ongoing process. If transition management concepts are found to be useful (by the participants themselves), a next suggestion would be to translate transition-terminology into a context-specific 'local language' before bringing it in to a project. Such translation should not be done by an outsider who imposes it onto the project. Instead of formally requiring participants to translate their project in terms of the strategic Transumo language, it should be explored whether and how participants could use transition management ideas to (re)conceptualize their project themes. In some cases, it might be preferable to translate the ideas of transition management into a less abstract and more contextspecific language. In that way, participants can develop their own language and use it on the basis of intrinsic motivation. Rather than presenting transition management as something required by Transumo, academia or the government, it can be positioned as a set of concepts that project-managers and participants can use to empower themselves to deal with context-specific challenges. That way they are deliberately using transition management concepts instead of being 'pawns' in a wider transition discourse.

Empowering incumbent managers and participants

While transition management aims to empower 'frontrunners' and 'niche-actors', it also has some exclusive elements in terms of actor-selection. The literature states that:

\footnotetext{
${ }^{20}$ Through scenario and back-casting exercises, and the concept of different 'transition paths' (Kemp and Rotmans 2009; Sondeijker et al. 2006; Loorbach 2007).

21 Through participative techniques, e.g., the SCENE-model (Grosskurth and Rotmans 2005; Loorbach 2007).
} 
"participants in the transition arena need to have some basic competences at their disposal: they need to be able to think at a high level of abstraction (system thinking), be able to communicate abstract ideas and have leadership abilities" (Loorbach 2007, p. 140). The provided list of criteria includes networking skills, systems thinking, guts, ambition, abstract thinking, strategic thinking, creativity and imagination, problem structuring skills, general knowledge, a large network, vision, communication and negotiation skills, and so on (ibid). Individuals that meet these criteria, are by definition already 'empowered'. The idea in transition management is that by bringing them together in a so-called 'arena', they can further empower each other (creating an 'empowered niche-network'), and then move on to empower others.

However, when 'transitioning' ongoing programs and projects, actor-selection has already taken place. Pointing out that these actors do not fulfill the criteria of the ideal 'frontrunners' as described in transition management literature can disempower incumbent participants. As we saw in our case-study, the Transumo organization provides training workshops on transition management. In such workshops, there is a thin line between motivating participants to improve and giving them the feeling they are incompetent. To complicate things further, this line is different for every individual. Some prefer direct constructive criticism to overly positive motivational discourse. Instead of 'one-size-fits all' trainings, the focus could be on individual training, and practical advice on how to deal with context-specific dilemmas that come up within projects. Moreover, it may be more effective to focus on the competences that incumbent participants do have, rather than on the competences they lack. As pointed out in the empowerment literature: people "already possess a great deal of power-power that resides in their knowledge, experience, and internal motivation," and they must just "acquire the skills and desire to use the power they [already] possess" (Randolph 2000, pp. 95-99). Furthermore, empowerment research stresses the importance of understanding why people are not being the innovative, risktaking, and long-term oriented individuals that others want them to be. This is not necessarily because they are not committed to societal goals, incapable of creative thinking or lacking some personality traits. It may be that they simply have a history of working with risk-avoidance, compliance, and short-term success. The literature on empowerment emphasizes that most managers and change professionals fail to understand that empowerment requires a long-lasting exposure to a 'safe' environment in which people are encouraged and allowed to work on the basis of intrinsic motivation. Therein, it is important for those responsible for creating such an environment, to not 'fall back' into commandand-control thinking or use management techniques that reinforce extrinsic motivation. In the three projects under study the time-consuming formal procedures imposed extrinsic motivation and distracted participants from focusing on intrinsically motivated tasks.

One suggestion would be to reconsider the subsidy-regulations designed by the government and to avoid that a long-term policy ambition such as 'a transition to sustainability' is operationalized through projects and programs that are 'stuck' in a hierarchical and bureaucratic construct. However, there is also something that can be done at the level of programs and projects, i.e., to deal with the given imposed formal procedures in a more 'creative' manner. Empowered individuals "ask for forgiveness rather that permission" (Quinn and Spreitzer 1997, p. 38). Not only can this philosophy be applied to the subsidyregulations, but programs and projects can also use it to deal with these given procedures: instead of having participants formally ask for 'permission' to start or continue a project, the focus could be shifted to a more informal form of retrospective accountability (e.g., oral presentations instead of formal reports, involving entire team-responsibility instead of individual responsiveness by project leaders only). 
Dealing with power relations beyond 'participation'

In our empirical case-study, we saw that managers feared that involving more 'nicheactors', or giving participating niche-actors more influence, could upset the 'regime-participants'. Transition management processes occur within a system that has certain power structures. According to critical theorists, it is questionable to what extent power relations can be substantially altered at the interpersonal level of a 'transition project'. In this respect, empowerment literature is helpful to stress that it is not about a manager 'giving' niche-actors more power or 'taking it away' from regime-actors. The manager does not need to choose sides or 'speak on behalf' of anyone. Rather, it is about creating a setting in which niche-actors can empower themselves, by being allowed to speak their minds and openly disagree with regime-actors. In this regard the 'niche-regime discourse' as found in transition management has an empowering potential that has not been exploited in projects as the ones studied. The mere idea of searching an opportunity to go beyond the existing, dominant regime can be empowering in itself. This empowering potential does not only apply to niche-actors, but also to actors operating within the regime. Rather than using regime-niche discourse as something to oppose regime-players, it can be used to actually engage with regime-players in a different way. These players can be approached as 'enlightened regime-players' or 'niche-players within the regime': individuals that operate within regime structures but have the will and courage to change these regime structures. Rather than confirming their regime-characteristics or labeling them as opponents of innovation, they are welcomed as crucial partners to realize 'the transition'. Such attitude toward regime-players can have empowering effects, as it creates a sense of liberation from the regime-structures they are daily confronted with. Playing the role of 'enlightened regime player' in an innovation project can increase a sense of impact, meaning and choice. Of course, empowerment is not reached by just sticking the label of 'enlightened regime players' on to people, nor by simply allowing individuals to 'participate' in a transition project.

Perhaps the most important lesson to be learned from empowerment literature is that in fact 'participation' is not enough. Although 'participation' has often been equated to empowerment, both in terms of practical implementation and conceptualization, organizational psychologists argue that this equation is wrong because participation is only one aspect of empowerment (Conger and Kanungo 1988, Thomas and Velthouse 1990). They argue that 'participation' is mainly focused on providing a sense of 'choice', and that participatory management techniques often fail because they lack the other positive task assessments that are necessary for intrinsic motivation: a sense of meaning, competence, and impact. The extent to which individuals gain a sense of meaning, competence, and impact, depends on their interpretative styles; how they attribute causal relations related to their actions, how they evaluate them based on certain standards of success and failure and how they envision the future in terms of visualizing or anticipating what could happen (Thomas and Velthouse 1990, pp. 675-676). While transition management instruments are generally described as 'participatory techniques', insights on intrinsic motivation help to specify those elements of transition management that move beyond mere participation. There are several tools in transition management that facilitate interpretative processes that can foster all sources of intrinsic motivation, such as long-term transition scenarios ('envisioning future events'), integrated system analysis, problem-structuring, and midterm back-casting ('attributing cause and effect') and experimentation and learning rather than producing short-term results ('evaluating success and failure'). These instruments can be used by individuals to position their own actions within larger societal developments. 
Instead of labeling company representatives as 'only caring about the short term' (as happened in the observed projects), they can be positioned as individuals that can contribute to long-term societal improvement, and challenged to do so.

Besides the role that 'process-facilitators' can play by using these instruments in project meetings, critical theorists emphasize that power is a self-developing capacity and that empowerment has to come 'from within'. In this respect, researchers or process-advisors can only 'state' that managers and participant can exercise power, if they choose to do so. For instance, Transumo finances $50 \%$ of its projects through government subsidies, which are officially designed to serve long-term sustainability goals. If powerful business stakeholders want to insist on applied research results for short-term profit purposes, they can hire consultants to do so, rather than participating in a Transumo-project. Stakeholders can be reminded of this when necessary and Transumo managers have a position to do so. Another comment in the line of critical theory is that it would not hurt Transumo-projects, such as the A15-project, to actually involve some 'victims' of unsustainable transport that belong to groups that are 'weak' (such as the low income inhabitants of the A15-region or smaller transporting companies - as discussed in "Case-study: applying transition management to ongoing projects on sustainable transport" section). Besides moral grounds and the issue of democracy, the direct confrontation with grass-root problems also has a purely instrumental benefit as it empowers participants by emphasizing that their project is actually 'making a difference' Table 3 .

\section{Conclusion: empowerment and long-term policy design}

This article has discussed how the implementation of a long-term design, i.e., transition management, can come with considerable (dis)empowerment issues at lower operational levels. Even if the long-term policy is celebrated in high strategic circles, managers and participants at lower organizational levels may feel estranged by these broad new ambitions, and fail to act as expected. Policy-designs that aim to move away from control-andcommand toward 'learning' and 'participation', may be surprised to find that many actors are quite comfortably accustomed to hierarchy, short-term targets and extrinsic motivation, and not so eager to engage in 'bottom-up initiatives', long-term horizons and innovation. For these individuals, the introduction of a new policy language (e.g., transition discourse) and subsequent new actor roles, can even have considerable disempowering effects, if the alienating circumstances are not positively related to their own sense of impact, meaning and competence. In that case the spread of 'participative events' all throughout a policy field may even have counter-productive effects, as the 'participants' may be confirmed in their overall impression that they are pawns in some new policy trend. Despite of the enthusiasm surrounding 'participation', 'involving' actors at all organizational levels is not enough to actually motivate them. Although 'participation' helps to increase a sense of self-determination, this is not sufficient for individuals to feel intrinsically committed toward a new policy cause. According to empowerment insights provided by organizational psychology, individuals also need a sense of meaning, competence and impact with regard to their own everyday tasks, which depends on the way they interpret and assess these tasks in relation to long-term policy ambitions. If such positive task assessments are lacking, intrinsic motivation will be low, and high external costs are necessary to 'enforce' the new policy design, which may contradict with the underlying ideals of the desired new paradigm (i.e., participation, bottom-up dynamics etc.). 
Table 3 Overview: empowerment lessons on how to deal with transition management (TM) challenges

\begin{tabular}{l} 
Observed TM-challenges \\
\hline Participants struggled with \\
(imposed) transition \\
terminology \\
\\
Project-leaders were reluctant \\
and incapable of applying \\
transition management and \\
struggled with administrative \\
hassle
\end{tabular}

Unbalanced power relations and stereotypes between participants were confirmed and enforced within and outside the projects
Empowerment lessons on how to deal with TM-challenges

Transition terminology can benefit from empowerment insights and have a positive effect on sense of impact, competence, meaning and choice by: (1) considering whether transition concepts are considered appropriate/useful by participants themselves; (2) translating transition-terminology into a context-specific local language; (3) presenting TM as a set of concepts that participants can choose to deal with context-specific challenges

The participatory nature of TM requires a culture of empowerment. The shift from a hierarchical to empowerment culture requires long exposure to a safe working environment that encourages intrinsic motivation. The position of mid-level managers therein is difficult but crucial for organisational change and thus requires special support and training. Rather than one-size fits all trainings, focus should be on individual training and practical advice on how to deal with contextspecific dilemmas that come up at the operational level

It is not about a manager 'giving' niches more power or 'taking it away' from regimes, but about creating a setting in which niches are encouraged to challenge regimes. Powerful regime-actors should not be positioned as enemies of change but challenged as individuals that can change regime structures (=>positive effect on sense of choice, impact, meaning and competence). Managers of tripartite projects have the authority to stand up against one-sided stakeholder demands and should be encouraged to do so. Weaker segments of society most victimized by unsustainable practices should be involved in 'transition projects'; besides moral and democratic concerns, this would also have an instrumental benefit as it positively affects other participants' sense of impact

One should avoid that 'transitioning' processes are implemented in a hierarchical context through mechanisms that reinforce extrinsic motivation. In ongoing projects TM should be presented as a set of concepts \& tools that incumbent managers can use (e.g.. scenario exercises or integrated system analyses) to motivate their project participants toward change and innovation. Psychological insights on empowerment help to explain how these TM-tools 'go beyond' mere participation and can be used to facilitate interpretative processes that are necessary for intrinsic motivation and commitment to project goals. With regard to actor-selection, it is more effective to focus on competences that incumbent participants do have, than on the competences they lack

Long-term policies such as 'transition policy' deserve considerable attention to their (dis)empowering mechanisms at operational levels, both in their design and evaluation. In a critical line of argument, due skepticism and critical analysis toward long-term policies seems both appropriate and necessary. In a more instrumental line of argument, it is necessary to integrate empowerment insights within a policy design, taking into account the vast body of research that demonstrates how many 'participation' initiatives fail due to an insufficient understanding of the inherent contradictions of empowerment. The mere concept of one actor 'empowering' another actor is philosophically contradictory, as the subsequent dependency relations are inherently disempowering. Designing a perfectly 'empowering' or 'participative' policy process is simply impossible. The challenge is to be sensitive to the empowerment-paradoxes that emerge and to avoid that the disempowering 
effects come to prevail over the empowering ones. Not doing so can result in policymakers using tools that enforce extrinsic motivation at the cost of intrinsic motivation (e.g., higher financial rewards, administrative obligations, competitive awards etc.), a strategy that is not only disempowering (as it increases dependency) but also 'wears off' with use.

Finally, empowerment insights address an important issue in long-term policy: "who gets what, when, and how" (Lasswell 1936 in Schneider and Ingram 1993). This article included an example of 800 million Euros being spent on 'applied research projects' that are expected to 'contribute to transitions to sustainability'. These projects mostly feature science, business and government, while the weaker segments of society, who can be said to suffer the most from 'unsustainability', are not involved. This is not a surprising phenomenon, as there are strong pressures for public officials to "provide beneficial policy" to groups that are powerful and positively constructed, even though these groups may have lesser 'need' for government support (Schneider and Ingram 1993, p. 334). Business and scientists are typical examples of such powerful and positively viewed groups that are favored in distributive policies. The legitimizing rationales used by government "feature the group's instrumental links to the achievement of important public purposes and economic competitiveness" and "achieving the instrumental goals of policy will be emphasized as the reason for the selection of particular target groups" (ibid. p. 339). This quite literally reminds us of the 'mission' of the organization in our case-study: Transumo contributes to "advances that help to strengthen the competitiveness of the Dutch transport sector (profit) and to preserve and improve spatial and ecological (Planet), and social (People) aspects of mobility" (website Transumo). Long-term policies are often geared toward goals such as sustainable development, welfare, economic competitiveness, quality of life, and so on. As these goals require actors that can 'think strategically' and influence future events, long-term policies may have a tendency to primarily involve big business, science, and government.

But what happens to other people? In an era of 'sustainability' discourse, the first P of the people-planet-profit-balance is often forgotten as discussions submerge in quantitative squabbling over cost-benefit analysis and trade-offs between ecological and economic targets. Many individuals (i.e., all those who are not in science, big business, or government) do not directly identify with a future characterized by economic and environmental targets, nor do they feel its proclaimed urgency. If the social dimension is mentioned at all, it often refers to the supposed demands of the 'consumer-citizen'. When the 'social aspect' of 'sustainable transport' is dealt with, 'people' are not referred to as ends in themselves but mostly as aggregate subjects that 'demand' economically and environmentally viable mobility. A reorientation toward the empowerment aspects of long-terms goals such as 'sustainability' would give a deeper meaning to the 'people'-aspect. Besides democratic concerns and other moral grounds, the 'empowerment of people' as an end in itself also has instrumental benefits; the idea that one is actually doing something 'for people' can heighten intrinsic motivation and thereby contribute to a willing accomplishment of longterm policy goals.

Acknowledgments I wish to thank the guest editors, Jan-Peter Voss, Adrian Smith, and John Grin for their many helpful comments and encouragements on earlier versions of this text. I would like to express a special gratitude to Jan-Peter Voss for all his time and effort in providing thorough suggestions. Furthermore I want to thank Jan Rotmans, Eefje Cuppen, Suzanne van der Bosch en Roel van Raak for their comments and suggestions on various versions of this article. The suggestions of the reviewers were also very helpful. Last but not least, I want to thank all the participants of the workshop on "Politics and Governance in Sustainable Socio-technological Transitions" (Berlin, September 2007) for allowing me to present and discuss with them the topic of this paper. 
Open Access This article is distributed under the terms of the Creative Commons Attribution Noncommercial License which permits any noncommercial use, distribution, and reproduction in any medium, provided the original author(s) and source are credited.

\section{References}

Argyris, C. (1998). Empowerment: The emperor's new clothes. Harvard Business Review, 76(3), 98-105.

Avelino, F., \& Bressers, N. (2008). Short versus long-term and other dichotomies: A challenge for transition management. Conference paper presented at the NECTAR workshop 'Transition towards sustainable mobility: The role of instruments, individuals and institutions', Erasmus University of Rotterdam, May 15-16, 2008.

Boje, D. M., \& Rosile, G. A. (2001). Where is the power in empowerment? Answers from Follet and Clegg. The Journal of Applied Behavioural Science, 37(1), 90-117.

Conger, J. A., \& Kanungo, R. N. (1988). The empowerment process: Integrating theory and practice. Academy of Management Review, 13(3), 471-482.

Grosskurth, J., \& Rotmans, J. (2005). The scene model: Getting a grip on sustainable development in policy making. Journal Environment, Development and Sustainability, 7(1), 135-151.

Gruber, J., \& Trickett, E. J. (1987). Can we empower others? The paradox of empowerment in the governing of an alternative Public School. American Journal of Community Psychology, 15(3), 353-366.

Hajer, M. A. (1995). The politics of environmental discourse: Ecological modernisation and the policy process. Oxford: Clarendon Press.

Hardy, C., \& Leiba-O'Sullivan, S. (1998). The Power behind empowerment: Implications for research and practice. Human Relations, 51(4), 451-483.

Juhl, H. J., Kristensen, K., Dahlgaard, J. J., \& Kanji, G. K. (1997). Empowerment and organizational structure. Total Quality Management, 8(1), 103-111.

Kanter, R. M., Stein, B. A., \& Jick, T. D. (1992). The challenge of organisational change. New York: The Free Press.

Keller, T., \& Danserau, F. (1995). Leadership and empowerment: A social exchange perspective. Human Relations, 48(2), 127-146.

Kemp, R., \& Rotmans, J. (2009). Transitioning policy: Co-production of a new strategic framework for energy innovation policy in the Netherlands. Policy Sciences. doi:10.1007/s11077-009-9105-3.

Loorbach, D. (2007). Transition management: New mode of governance for sustainable development. PhD thesis. Erasmus University Rotterdam, Utrecht: International Books.

Nota Mobiliteit III (2005) Uitvoeringsagenda; van Nota naar Mobiliteit, V\&W en VROM.

Pressman, J. L., \& Wildavsky, A. (1973). Implementation, how great expectations in Washington are dashed in Oakland. Berkeley, CA: University of California Press.

Quinn, R. E., \& Spreitzer, G. M. (1997). The road to empowerment: Seven questions every leader should consider. Organizational Dynamics, 26(2), 37-49.

Randolph, W. A. (2000). Re-thinking empowerment: Why is it so hard to achieve? Organizational Dynamics, 29(2), 94-107.

Rotmans, J. (2003). Transitiemanagement; Sleutel voor een Duurzame Samenleving. Assen, Netherlands: Koninklijke van Gorcum.

Rotmans, J. (2005). Societal innovation: Between dream and reality lies complexity. Inaugural speech. Rotterdam: Erasmus Research Institute of Management.

Rotmans, J., Kemp, R., \& Asselt, M. (2001). More evolution than revolution: Transition management in public policy. The Journal of Futures Studies, Strategic Thinking and Policy, 3(1), 15-32.

Schneider, A., \& Ingram, H. (1990). Behavioral assumptions of policy tools. Journal of Politics, 52(2), 510529.

Schneider, A., \& Ingram, H. (1993). Social construction of target populations: Implications for politics and policy. American Political Science Review, 87(2), 334-347.

Smith, A., \& Kern, F. (2007). The transitions discourse in the ecological modernisation of the Netherlands. 57th political studies association annual conference, University of Bath, April 11-13, 2007.

Sondeijker, S., Geurts, J., Rotmans, J., \& Tukker, A. (2006). Imagining sustainability: The added value of transition scenarios in transition management. Foresight, 8(5), 15-30.

Spreitzer, G. M., De Janasz, S. C., \& Quinn, R. E. (1999). Empowered to lead: The role of psychological empowerment in leadership. Journal of Organizational Behavior, 20(4), 511-527.

Thomas, K. W., \& Velthouse, B. A. (1990). Cognitive elements of empowerment: An "interpretative" model of intrinsic task motivation. Academy of Management Review, 15(4), 666-681. 
Van den Bosch, S., \& Rotmans, J. (2008). Deepening, broadening and scaling up: A framework for steering transition experiments. Essay 02. Knowledge Centre for Sustainable System Innovations and Transitions (KCT): Delft and Rotterdam.

Voß, J-P., Smith, A., Grin, J. (2009). Designing long-term policy: Rethinking transition management. Policy Sciences. doi:10.1007/s11077-009-9103-5. 